\title{
Deep and Extreme Child Poverty in Rich and Poor Nations: Lessons from Atkinson for the Fight Against Child Poverty
}

\author{
Yixia Cai ${ }^{1}$ D $\cdot$ Timothy Smeeding ${ }^{1}$
}

Received: 20 May 2019 / Accepted: 3 October 2019 / Published online: 24 October 2019

(c) The Author(s) 2019

\begin{abstract}
The paper documents child poverty levels and trends using both relative ('deep') and absolute ('extreme') measures in two clusters: Anglo-Saxon high-income countries and upper middle-income countries. We also investigate the influence of different components of household income and other resources on child deep-poverty rates to examine the role of the market and the redistributive effects that materialize through private transfers, public benefits, and tax systems on generating poverty reduction. Overall, middle-income nations have witnessed continuous reductions in their extreme child poverty rates, while mild decreases or fluctuations have been observed in the five high-income nations, with the US highlighted by its relatively high rates of deep and extreme poverty regardless of absolute or relative measures and type of equivalence scale used. Private institutions play a larger role in poverty reduction in middle-income nations compared to its impact on developed nations. The degree of dependence on universal or assistance benefits varies among high-income nation. In the US, universal programs tend to be meager, while Australian social insurance and universal benefit are robust in their fight against deep poverty. Brazil stands out by its overwhelmingly large proportion of social insurance programs that contribute to improvements of its deep child poverty situation, and South Africa's assistance benefit system performs better in lifting children out of deep poverty.
\end{abstract}

Keywords Child poverty $\cdot$ Universal benefits $\cdot$ Social assistance $\cdot$ Cross-national comparison

This paper was prepared for the LIS user's conference in honor of Tony Atkinson, May 3-4, 2018. We would like to thank Stephen Jenkins and Anne-Catherine Guio for their comments on an earlier draft. We also thank two anonymous reviewers for their feedback. The support of the WARF professorship at the University of Wisconsin-Madison is greatly appreciated.

Yixia Cai

yixia.cai@wisc.edu

Timothy Smeeding

smeeding@1afollette.wisc.edu

1 University of Wisconsin-Madison, Madison, USA 
JEL Classification I30 $\cdot$ I32 $\cdot$ I38

\section{Introduction}

Child poverty has drawn increasing attention from social scientists and policy makers in the past decades. Nations should be judged on how they treat their children, especially those facing the uninsurable risk of being born to parents who are unable or unwilling to support them. A number of studies from developed countries illustrate the negative effects of children living in poverty, especially deep poverty (incomes less than half of the poverty line) on their future development. These include chronic health and psychological problems as well as poor educational attainment compared to their middle class and affluent peers in rich countries (Almond et al. 2018; Magnuson and Votruba-Drzal 2008; Rainwater and Smeeding 2003; Smeeding and Thévenot 2016).

In some less-developed but still rapidly growing nations, extreme child poverty (incomes per person below $\$ 2.00$ per day) is still a major issue. Although some doubt the goal will be reached, governments around the world have committed to a new set of sustainable development goals (SDGs) that include ending extreme poverty for everyone and everywhere by 2030 (Gertz and Kharas 2018; World Bank 2018b). Usually, to examine the extremely disadvantaged, the World Bank conducts studies using spotty microdata and methods that are not used to measure poverty in rich countries, but new efforts on shared prosperity and poverty reduction at higher income and poverty line levels have improved these estimates while generating new challenges for policy and poverty (World Bank 2018b). In addition, the family size adjustments that were used in earlier reports assume no economies of scale in household consumption. We will also overcome this obstacle in the paper.

Deep and extreme poverty issues have recently surfaced in very rich but unequal nations such as the US. Nobel laureate Angus Deaton (2018) points to high levels of extreme disadvantage in the US, citing a stunning UN report on US poverty by Alston (2017), United Nations Special Rapporteur on extreme poverty and human rights. Alston found very poor child conditions such as ringworm and toothless children due to dental decay in his examination of poverty in various areas in the US. Deaton goes on to compare poverty in rich and poor countries, using a method invented by Allen (2017); Deaton claims that "there are 5.3 million Americans who are absolutely poor by global standards. This is a small number compared with the one for India, for example, but it is more than in Sierra Leone (3.2 million) or Nepal (2.5 million), about the same as in Senegal (5.3 million) and only one-third less than in Angola (7.4 million)." Approximately half of the people in deep poverty are children (Stevens 2019). Hence, rich nations are becoming aware of extreme poverty in their midst (see also Edin and Shaefer 2015).

As major emerging nations experience income growth, they begin to look more like rich Western nations, especially in cities and urban areas and even in remote rural areas. In this paper, we examine child poverty in a set of emerging nations: Brazil, China, India and the Republic of South Africa (RSA), and in another set of large and rich English-speaking nations: Australia, Canada, Ireland, the United 
Kingdom (UK) and the United States (US). Taken together, these countries include about a third of the world's population and more than $25 \%$ of all children.

The aim of our paper is to consistently measure relative ("deep") and absolute ("extreme") child poverty in a more global context, using a set of rich and poor nations, and to think about what could be done to alleviate these conditions. Three different institutions (including the market-driven aspect, private redistribution through inter-household transfers, and traditional public redistribution through cash transfers and tax systems) are also recognized, especially because of their differences across nations. The Luxembourg Income Study (LIS) (2019) allows us to consistently examine differences in child poverty using multiple poverty measures, multiple periods and a collection of income measures in a fully flexible and comparable way.

The paper is very much in line with Tony Atkinson's concerns for poor children as expressed in his recent research on global poverty with the World Bank, in his work with rich countries such as LIS and his prescriptions for ending poverty among children in all nations (Atkinson 2015, 2016). We say this knowing that Tony would be aghast at the depth of child poverty that we explore here, far below the $60 \%$ of national median poverty standards that he repeatedly defended and upheld (e.g. Atkinson 2015).

We structured the paper as follows. Below we look at the major current child poverty issues in poor and rich nations. The data and methods are presented in the third section, which is followed by results on child poverty levels and trends in nine countries of interest using both relative and absolute measures from 2002 to the most current year. We also analyze the influence of the different components of household income resources on deep-child-poverty rates in order to examine the role of market and redistributive effects, which materialize through transfers and child benefits, on poverty reduction. We close the paper with a discussion of the further implications for effective interventions that improve children's life chances in a local context.

\section{Background on Issues Surrounding Deep and Extreme Child Poverty}

With increasing economic growth, most of the world's poor live in countries that are being reclassified as middle-income countries (MICs) from previous low-income country clusters. More than $70 \%$ of the global poor live in MICs (Kanbur 2012; World Bank 2018a). In addition, increasingly, those who are used to living in lowincome countries tend to migrate to MICs (Kanbur and Sumner 2012), making it more promising to tackle child poverty in a global context, as MICs have relatively fewer financial constraints and fiscal dividends from growth that can be sued for reducing poverty among their next generations compared with their low-income counterparts. Our selected nations are excellent examples of this emergence. Table 1 shows the progress of our four emerging nations using the World Bank's 2018 measures for poor or low-income nations (L), lower middle-income nations (LM), upper middle-income countries (UM) and rich countries (R). Brazil, which was LM in 2002, quickly reached UM in 2006 and may soon join the R nations; China went 
Table 1 Historical classification by income among four middle-income countries

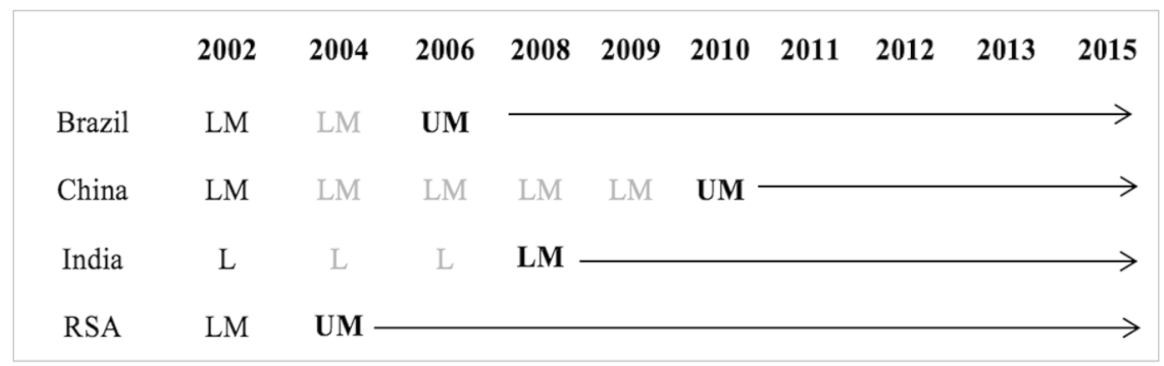

Note: $\mathrm{LM}=$ Lower middle income; $\mathrm{UM}=$ Upper middle income; $\mathrm{L}=$ Low income; RSA = the Republic of South Africa; Source: World Bank (2018a)

from LM in 2002 to UM by 2010; India has progressed from L to LM between 2002 and 2008 and South Africa jumped from LM to UM and has remained there early in the 2000s.

Notwithstanding increasing economic growth in these nations, reducing childhood poverty remains a challenge due to less formal and effective social safety net programs in developing countries, and a nontrivial proportion of private transfers flow between households are observed in middle-income countries (Cai and Evans 2018), which to some extent act as crucial financial support to buffer severe deprivation. According to a report by UNICEF and World Bank Group (2016), over 30\% of the world's poorest children live in India, struggling with $\$ 1.90$ or less per person daily, ${ }^{1}$ and more than $50 \%$ of the nation's children live in poverty in South Africa. In all of these nations, a high level of resource inequality makes tackling child poverty problems more difficult both due to the high disparity in the distribution of economic resources as well as ethnic and racial differences, especially in India and the RSA. South Africa remains the country with the highest income inequality in the world and the country with the highest fraction of low-income Blacks (Sulia and Zikhali 2018).

Poverty rates among children in middle-income countries in the LIS Database have remained overwhelmingly higher than those in high-income countries, using either relative or absolute measures (Gornick and Jäntti 2012). Still, others have called attention to the role of within-country policies that influence child poverty reduction in LM and UM countries. The positive effects of conditional cash transfer programs in reducing child poverty have been cited in Brazil (Shei et al. 2014), South Africa (Engle et al. 2011), and Mexico (Fernald et al. 2008; Fernald et al. 2009). The targeted policy progress of the Child Support Grant in South Africa has relieved financial stress among impoverished families and improved the well-being of poor children living in such families (SAHRC and UNICEF 2016). Most recently, the emergence of the welfare state and anti-poverty policy in China has been documented as well as the effects of their national war on poverty (Gao 2017, 2018).

\footnotetext{
${ }^{1}$ Even more striking, the share of the world's extremely poor children in Sub-Saharan Africa is approximately $50 \%$ today.
} 
In rich countries, deep child poverty continues to persist despite the great wealth of others in English-speaking nations. We find an armada of income support and redistribution policies aimed at helping poor children, but not all English-speaking nations provide these. Among the five countries we investigate, all but the US have a universal child allowance. In addition, the UK's war on child poverty is still very robust (Waldfogel 2010), while Canada has recently introduced a very generous universal child benefit that will almost halve relative child poverty in that nation by the end of 2018 (Corak 2017).

However, the trend in the US has been the reverse: it has increasingly transferred income support from the desperately poor with little or no earnings to the working poor (Moffitt and Pauley 2018) and increasingly, work requirements are being added to almost all targeted income support policies for food, housing, and even medical care (Trump 2018). This phenomenon has also been sparked by the emergence of a study on families with children living on less than $\$ 2$ per person per day (Edin and Shaefer 2015). While some question the $\$ 2$ poverty measure and the length of time a family might be in such straits, there is an emerging belief that instability and lack of access to credit drive many families with children to this position at some point within a given year and that in fact deep poverty is rising (Jencks 2016).

Moreover, the US's recent call for 'welfare reform' to "promote opportunity and mobility" by testing all programs and reducing access to the already small safety net will produce even more deeply poor families with children (Trump 2018). This is especially true among US-born children of immigrants, where the immigrant parents of US citizen children are being removed from the nation and separated from their children (Heinrich 2018). Hence, the topic of the paper is an important concern in all nations, rich and emerging.

\section{Data, Measure and Methods}

Our analyses of deep and extreme child poverty throughout the paper are drawn upon harmonized microdata from the Luxembourg Income Study Database (LIS), which has been a pioneer in collecting a series of internationally comparable household survey data. Most recently, the database has expanded its traditional scope of the partner countries from the rich OECD world and included a series of MICs to strengthen its commitment to global poverty and inequality studies (Gornick and Jäntti 2012; Gornick and Nell 2017). An additional merit of the LIS database ${ }^{2}$ is the detailed disaggregation of social program provisions for each country participating in the database. In this way, we can identify the role of the market and redistributive effects from private transfers, living arrangements, social benefits and the tax system (Gornick and Smeeding 2018).

We use both relative ("deep") and absolute ("extreme") poverty measures (Smeeding 2016), comparing and contrasting levels and trends across the four emerging nations and the five rich ones. We refer to children living in families with

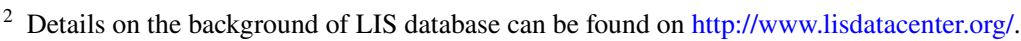


incomes below half of the "half median" poverty line $(25 \%$ of median equivalized income) as being in 'deep' poverty, while children living in families with incomes below a fixed dollar line (\$2 per person per day in MICs and \$6 per person per day in the rich nations) as being in 'extreme' poverty. Below, we describe in detail how we reach those measures of deep and extreme poverty.

For the purpose of comparability, the analysis sample consists of country data starting in the year 2002 and continuing to the most recent year available. Only households with children less than 18 years old are included when calculating the proportion of children living in poverty. Poor children are defined as those living in households whose income is below the thresholds mentioned above within each country. The analysis derived from disposable income includes labor income, transfer income, and capital income with the taxes and social security contributions subtracted. The disposable income is adjusted for differences in family size. All zero, negative or missing values of income were excluded from our samples. ${ }^{3}$ To provide evidence that estimates are not sensitive to how the negative- or zero-income are treated, we replicate analyses by considering two alternative treatments of such income [(a) exclude negative and zero income and simultaneously drop observations of those whose self-employed income is greater or equal to $50 \%$ of disposable income; (b) recode negative income to zero]. The results based on the last two approaches are very close to the ones separate from exclusion of negative and zero income (results are available upon request). Yet, we faced multiple measurement issues in assessing child poverty across countries with widely varying incomes and distributions within and between these nations. The role of household income is not limited to the overall poverty effect, but is also linked to fundamental issues of the measurement and adjustment of income and national price levels.

\subsection{Deep Child Poverty}

We start with the deep poverty concept, but choosing a certain percentage of median equivalized disposable income as the threshold has been an issue for many decades. In the LIS, traditional poverty rates are calculated at 40,50 and $60 \%$ of the median income. The highest relative line at $60 \%$ is the Ireland, European Union and UK poverty standard. The half-median line is the usual measure for international bodies, such as UNICEF, OECD and LIS. The lower $40 \%$ of the median standard is closest to the poverty lines in other English-speaking nations, such as the US. Deep poverty is measured at half the international relative measure, so $25 \%$ of the national median equivalised income is most comparable. Recent research (Fox 2017; Short

\footnotetext{
${ }^{3}$ We realize inclusion of negative or zero income could result in overestimated poverty rates because nontrivial self-employed people may be miscategorized as poor, especially in less-developed countries. We report that the approximate percent of observations in each country is dropped due to such exclusions: $2.8 \%$ BR (06), $2.7 \%$ BR (09), 5\% BR (11), 5\% BR (13), 3.7\% SA (08), 0.5\% SA (10), 0.7\% SA (15), $1.1 \%$ IN (04), $1 \%$ IN (11), $0.1 \% \mathrm{CN}(02), 0.5 \% \mathrm{CN}(13), 1.2 \% \mathrm{AU}(03), 0.6 \% \mathrm{AU}(08), 0.8 \% \mathrm{AU}$ (10), $0.8 \%$ AU (14), $0.2 \%$ CA (04), 0.1\% CA (07), 0.1\% CA (10), 0.07\% CA (13), $0.1 \%$ IE (04), $0.4 \%$ IE (07), $0.7 \%$ IE (10), $1.6 \%$ UK (04), $0.4 \%$ UK (07), $0.5 \%$ UK (10), $0.5 \%$ UK (13), $0.8 \%$ US (04), $1.2 \%$ US (07), $0.9 \%$ US (10), $0.8 \%$ US (13), $0.9 \%$ US (16).
} 
2013; Wimer and Smeeding 2017) suggests that the US's new supplemental poverty measure, which changes annually with per expenses spent by lower-income households, translates almost exactly to $40 \%$ of the median national adjusted income in the USA's most recent data in LIS Database as well as Canada's and Australia's LIS data. However, we understand that the creation of two relative poverty lines as benchmarks for a specific set of countries in the same study may result in interpretation complications. For the purpose of comparability, thus, for each country we examined, the paper uses relative poverty line- $25 \%$ of median equivalized income ${ }^{4}$ based on the level and distribution of household income among the total population.

\subsection{Extreme Child Poverty}

Regarding the extreme (absolute) poverty, the consensus in most comparative studies of poverty is that local currency of each country should be converted into international US dollars using purchasing power parities (PPP) to allow direct comparison of absolute poverty rates- "extreme poverty" in our paper. However, if living standard in different years or locations is not taken into account, measuring extreme poverty over time across countries would be problematic. In terms of the incorporation of the updated poverty research, recent article by Pinkovskiy and Sala-i-Martin (2018) and conventional practice suggest that the most recent PPPs are usually the best ones, as they increase in coverage, sophistication and quality with each round. We apply the 2011 PPP values between countries using the LIS year closest to 2011. Of equal importance, any absolute or anchored poverty line should be adjusted over time for inflation within countries using the harmonized national CPI during periods when research is conducted (Smeeding 2016).

The most prudent choice of a poverty threshold depends on the country, its context, and the time period under consideration. When it comes to adjusting poverty lines for family size, the equivalence scale matters a lot, as it measures the cost of providing an equal standard of living for households that differ by characteristics, such as ages of household members or the size of a household. The way that we consider the scales is presented in Eq. (1):

$$
S_{i}=\left(N_{i-a}+\gamma \times N_{i-c}\right)^{\theta}
$$

where $S$ is the total household size, computed in equivalent adults for household $i$. Ni- $a$ indicates the total number of adults present in household $i$, and similarly, $\mathrm{Ni}-\mathrm{C}$ is the number of children below the age of 18 in household $i$. The parameter $\gamma$ indexes the cost of a child's expenses relative to that of adults, while parameter $\theta$ represents the economies of scale regarding expenditures of household $i$. We test two different scales to determine our absolute measure. First, we assign both $\gamma$ and $\theta$ values of 1 , for which the number of equivalent adults is equal to the exact household size, leading to a per-capita-scale welfare measure. Alternatively, we set $\gamma$ to a value of 1 and let $\theta$ equal 0.5 , which refers to "LIS square root scale," in order to

\footnotetext{
${ }^{4}$ Relative poverty is measured in the LIS by first adjusting disposable household income per equivalent adult using the same square root scale.
} 
adjust poverty thresholds according to a given household's living standard and size. The extreme child poverty rates are expected to be higher under the first premise, especially for results from the MICs where large household sizes have no economies of scale using the per capita per day method.

Harmonized CPI data from LIS serves as the method that we use to arrive at a historical estimate of inflation. The procedure that led to the new household income for the specific years examined is specified in Eq. (2), where $I N C_{t}$ denotes income in international dollar for year $t$. Representing 2011 purchasing power parity exchange rates (US =1), the $2011 \mathrm{PPP}$ is used to adjust each national currency into 2011 international USD.

$$
I N C_{t}=\frac{\text { Income in local } \text { currency }_{t}}{2011 P P P}
$$

To reduce our estimate bias resulting from inflation and to retain the same real poverty line, the two fixed thresholds (e.g., \$2 and \$6) that we used were adjusted backward to the specified years for each country using the national CPI. An example is presented in Eq. (3), where $C P I_{t}$ indicates Consumer Price Index $(2011=100)$ for year $t$, and the adjusted poverty line $Y_{t}$ is based on the CPI for year $\mathrm{t}$.

$$
Y_{t}=\frac{\text { Fixedline }}{C P I_{t} / 100}
$$

The extreme poverty lines in the present paper are set as \$2 a day in MICs and \$6 a day in HICs. Our choice of this "semi-absolute" measure was derived to meet the need to develop a more comparable "societal poverty line," as proposed by Atkinson (2016). Even though technically an international poverty line of $\$ 2$ could represent a comparable way to track global poverty and evaluate progress on poverty reduction goals, this threshold is inadequate to meet the most basic needs for the developed world. It is estimated by the US Department of Agriculture that the minimum needed in the US to purchase food in 2011 was \$5.04 per day (Hickel 2015). Moreover, \$6 a day is more or less close to the 20th percentile of the Supplemental Poverty Measure developed by the US Census Bureau, which might more accurately represent daily needs of the extreme poor in developed nations.

Although estimating consumption poverty is beyond our present paper's scope, we intend to employ a better absolute approach, which takes into account a slight "relative" element of poverty, allowing for the variability of living standards and well-being across nations. This approach also closely aligns with the basic-need approach discussed in the latest report of better strategies to monitor global poverty, and it is necessary to note a "societal head count ratio approach" (Atkinson 2016). In addition, when it comes to using the absolute measure of $\$ 1.90$ a day per person to track global anti-poverty progress, some other proposals have been made that include a better set of thresholds meeting local needs (Allen 2017; Ravallion and Chen 2013). Thus, it is more appropriate to use a country's poverty line to better facilitate the policy discussion and to better target social programs that benefit the poorest children. In a further step of cross-national comparison between MICs and Anglo-Saxon nations, we compare the percentage of children living with less than 
$\$ 2$ a day from each of the four MICs to the proportion of children living below $\$ 6$ per day in five developed countries.

\subsection{Income Decomposition}

In addition to comparing the levels and trends of the poverty rates, we further decompose household income packages to assess the redistributive effects from different institutions. We start with sole market income to profile a big picture of market-driven monetary deep child poverty over time within each nation. We then take into account private transfer flow in influencing the overall ranking of deep child poverty. Following this, we factor in resources received from social insurance and universal programs in order to distinguish patterns of child outcomes in countries with or without universal programs. Lastly, we calculate deep child poverty rates when considering targeted transfers and tax payments (including refundable tax credits) in conjunction with previous income sources. Although the LIS database is the best cross-national archive that suits our needs for simultaneously and incrementally examining each of these income factors, some income definitions in several countries limit our analyses. For instance, there are some countries where universal benefits, targeted transfers, and tax payment could not be separately identified. The affected countries include Canada where universal program and assistance benefit data is unavailable in the years of 2004 and 2007; China, in which social insurance, universal programs and private transfers cannot be identified; India and Brazil where universal benefit data is unavailable. By proceeding with the best available data for the most recent year, after this decomposition exercise, we also calculate proportional changes to examine how the weights of each income component contributed to the national overall reduction in deep child poverty in the latest year.

\section{Results}

In Fig. 1, we show that the relative/deep poverty rates (panel A) among children across all countries of interest tend to remain flat across the whole period. Although some fluctuations are observable in Brazil and South Africa, whereas deep child poverty rates tended to be higher in India and China in the latest year relative to earlier points in time. This increase in relative poverty rates over the period examined may be due to growing inequality - real economic growth at the bottom of the distribution is lower for lower income families in these nations compared to the median income families (Alvaredo et al. 2017). Focusing on the most recent year (of available data) for each nation, China can be distinguished by having the lowest relative proportion (5\%) of children living in households with incomes lower than $25 \%$ of the median national disposable income; on China's heels are India (6.3\%), Brazil (9.2\%), and South Africa (11.6\%).

Turning to relative trends of the five developed nations (panel A), Ireland and UK appear to have relatively lower proportions of children living in households subsisting on less than $25 \%$ of median national equivalized income, while Australia's 


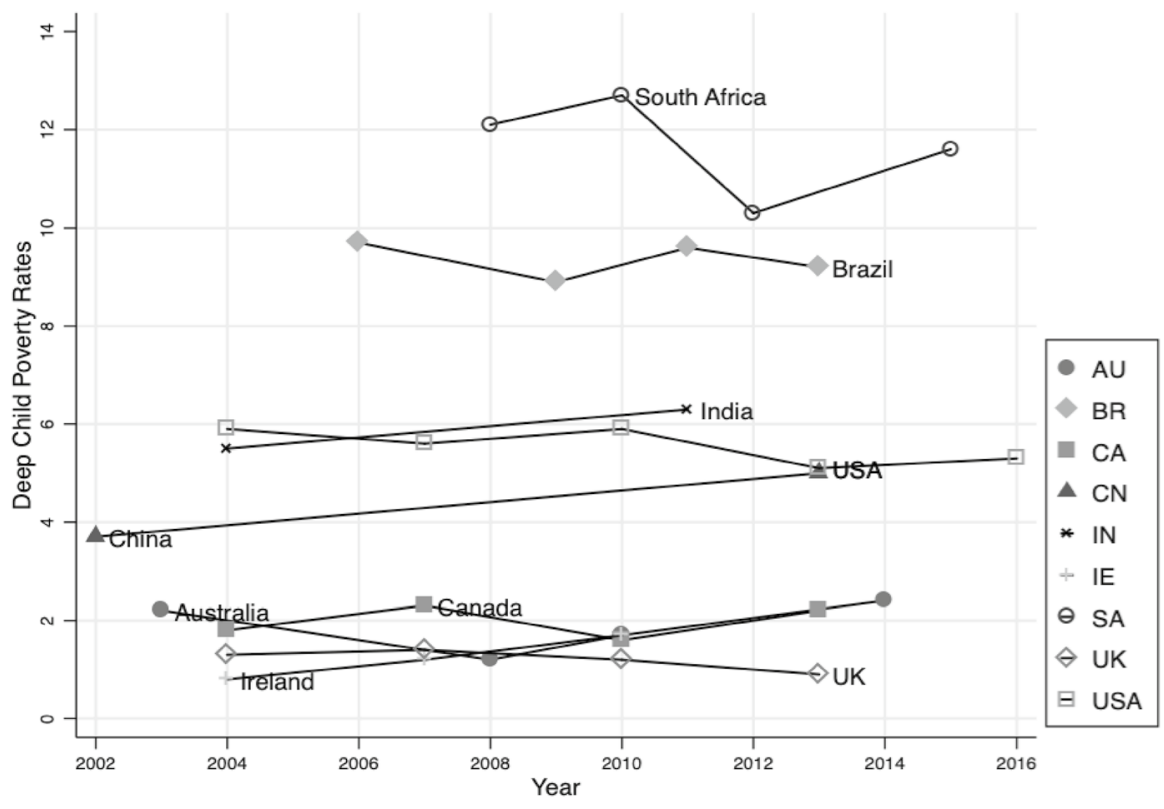

Fig. 1 Deep child poverty across countries. Source: Authors' calculation from LIS

relative line fluctuates, before it reaches $2.4 \%$ in 2014 . However, the US is the only developed nation we studied that struggles with relatively severe deep child poverty rates-approximately 5.6\% nationwide, ${ }^{5}$ between 2004 and 2016-using very comparable LIS data.

The overall picture in extreme child poverty rates (Fig. 2a, b) is very different when we deploy absolute measures. In addition to calculating the rates based on per-capita scale (2011 PPP adjusted), we also estimate percentage of children living in absolute extreme poverty using LIS equivalence scale to reflect economies of household size. Figure 2 a reports estimates of the proportions of children in four MICs, living on incomes of less than $\$ 2.00$ per day, based on two different equivalence scales (LIS square root and per-capita scale). The solid line is based on the per-capita scale, while the dashed line displays the trend based on LIS square root.

It is interesting to note that two sets of lines within each country are virtually parallel, while tending to converge for the most recent years. All the lines trend downward in all countries, regardless of the different definitions of equivalence scales; this reflects widespread economic growth across all four of these nations. As we expected, given that the per-capita scale fails to account for the concept of resource-sharing within households, the solid lines based on per capita measures for each nation are always higher than those dashed lines

\footnotetext{
${ }^{5}$ Given that the effect of self-employed income may have on our estimate of child poverty rates (i.e. negative income may be relevant to large assets, but it may not represent low living situation), we drop cases when their self-employed income is greater than or equal to $50 \%$ of disposable income, and re-estimate the deep child poverty rates in the US (available from the authors upon request). Result is consistent with the present version.
} 


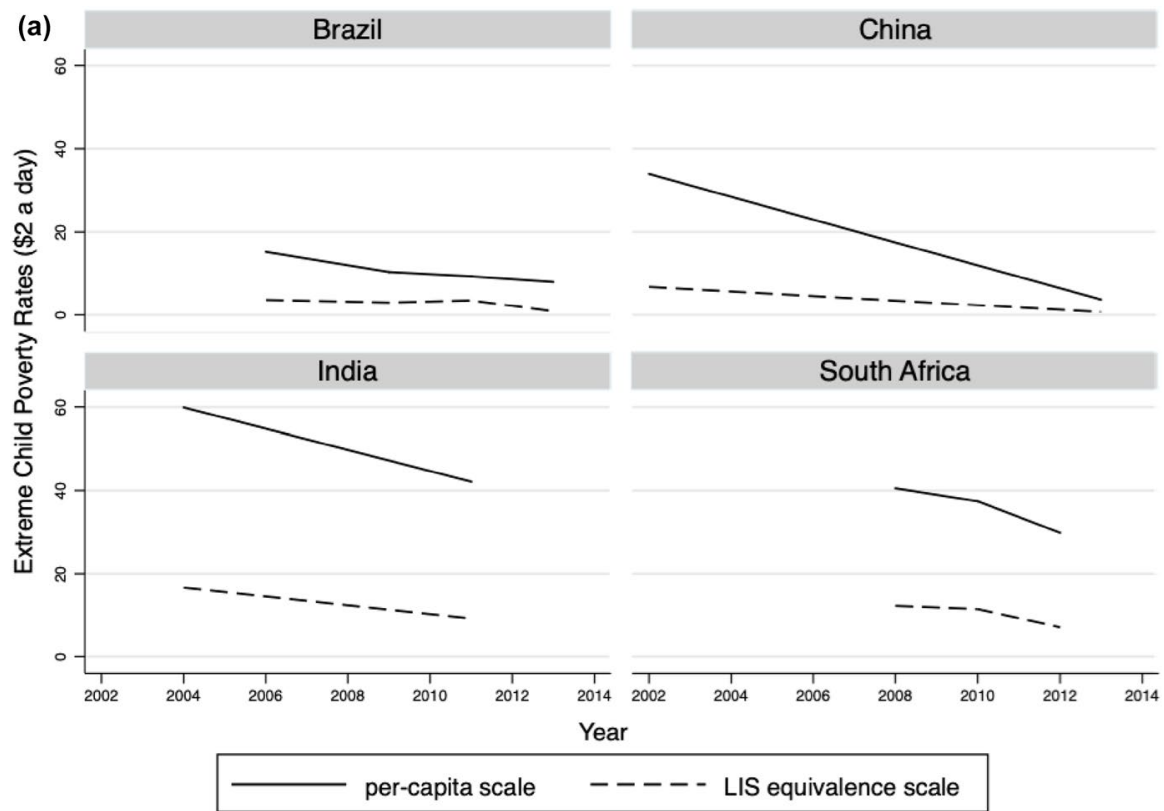

(b)
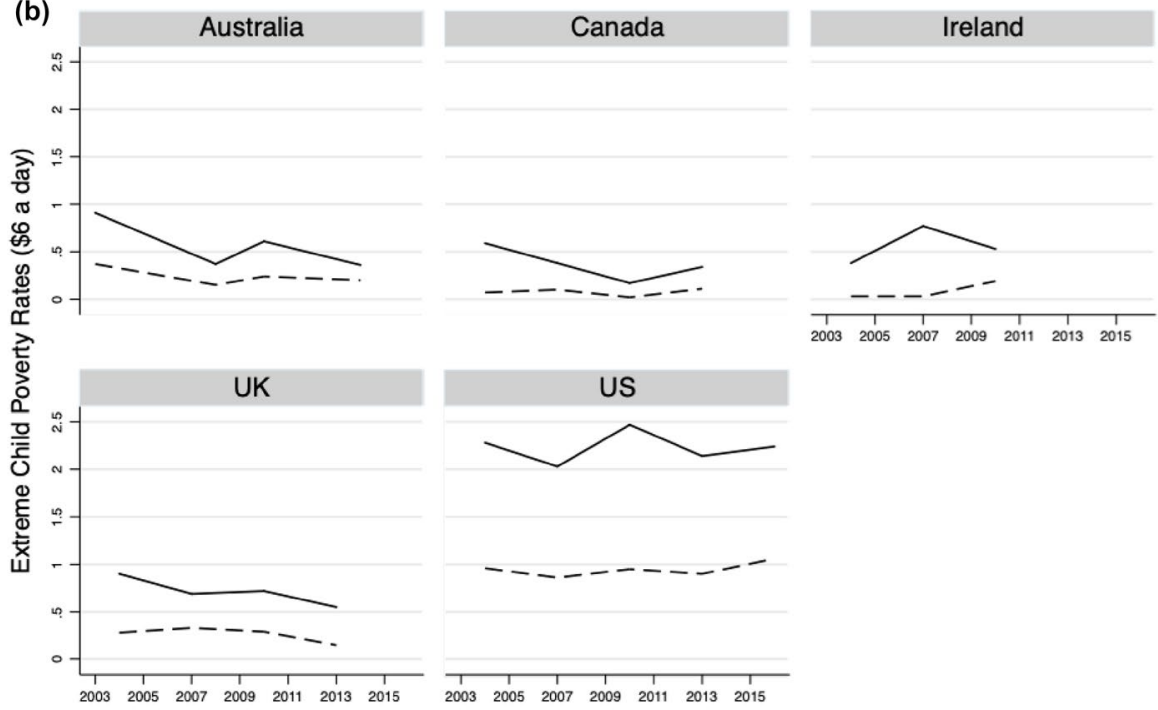

Year

Fig. 2 a Extreme child poverty across middle-income countries. b Extreme child poverty across highincome countries. Source: Authors' calculation from LIS 
representing extreme poverty rates that take economies of household size into account. Specifically, relative to the LIS square root, the per-capita scale measure reflects much higher rates of extreme poverty among children across these four countries, ranging from 2 to 5 times the poverty rates estimated using the LIS square root.

Results based on a per-capita scale indicate that the absolute national rate of extreme poverty among children in Brazil has decreased from 15\% in 2006 to $8 \%$ in 2013. It is also promising to note that China showed a sharp reduction (approximately $30 \%$ point) in the rate of extreme child poverty, from 34\% in 2002 to just slightly above $3 \%$ in 2013. Similarly, South Africa and India show reductions of $11 \%$ point and $18 \%$ point, respectively, in their national rates of extreme child poverty within a 7-year period.

Based on analyses that are not shown here, trends in both deep and extreme poverty in our four middle-income countries are driven by the growth of market incomes. Despite rising inequality in overall incomes in each country, the growth dividend at the bottom of the distribution has reduced extreme child poverty in all of the nations. A new global middle class is emerging as poverty falls (Gertz and Kharas 2018; World Bank 2018b).

Turning to absolute measures of the $\$ 6.00$-a-day line across five highincome countries (Fig. 2b), we observe a somewhat different conception of poverty reduction that we observed in Fig. 1 based on relative measures. Again, we display results based on both definitions of equivalence scales (either LIS square root or per-capita scale), as illustrated above for the MICs. Overall, starting in 2003, all five nations appear to achieve a modest reduction in their absolute rates of extreme child poverty after some fluctuations, while Canada and the US are notable for their unfavorably increasing proportion of children living on materially less than $\$ 6.00$ per day in the most recent year we examined. Again, the US stands out due to having the highest levels of extreme poverty in the most recent year (about 4-6 times the rates in other high-income nations examined). The success of British anti-poverty efforts aimed at children is evident based on constant reductions of rates, regardless of choice of equivalence scale.

The idea of the income package (Rainwater and Smeeding 2003) guides our analyses of why families may or may not be in deep poverty and the way the policy affects poverty rates. The income package includes incomes from three sources: those that are earned by the family per se (market incomes); those that come from other family members, including implicitly the economies of scale from larger household units, and private transfers across households, including remittances; and finally the effects of the state on income support, measuring net benefits (taxes paid minus benefits received).

For the rest of the analyses, we focus on data from the most recent year available for each country and describe our results. Figure $3 a, b$ show the results of an analysis of deep child poverty rates, ${ }^{6}$ which are based on calculations using $25 \%$ of the

\footnotetext{
${ }^{6}$ We also calculate the extreme child poverty rates (\$6 per day per person in developed nations and $\$ 2$ per day per person in MICs) over time based on each component of a given household's economic resources (available from the authors upon request).
} 


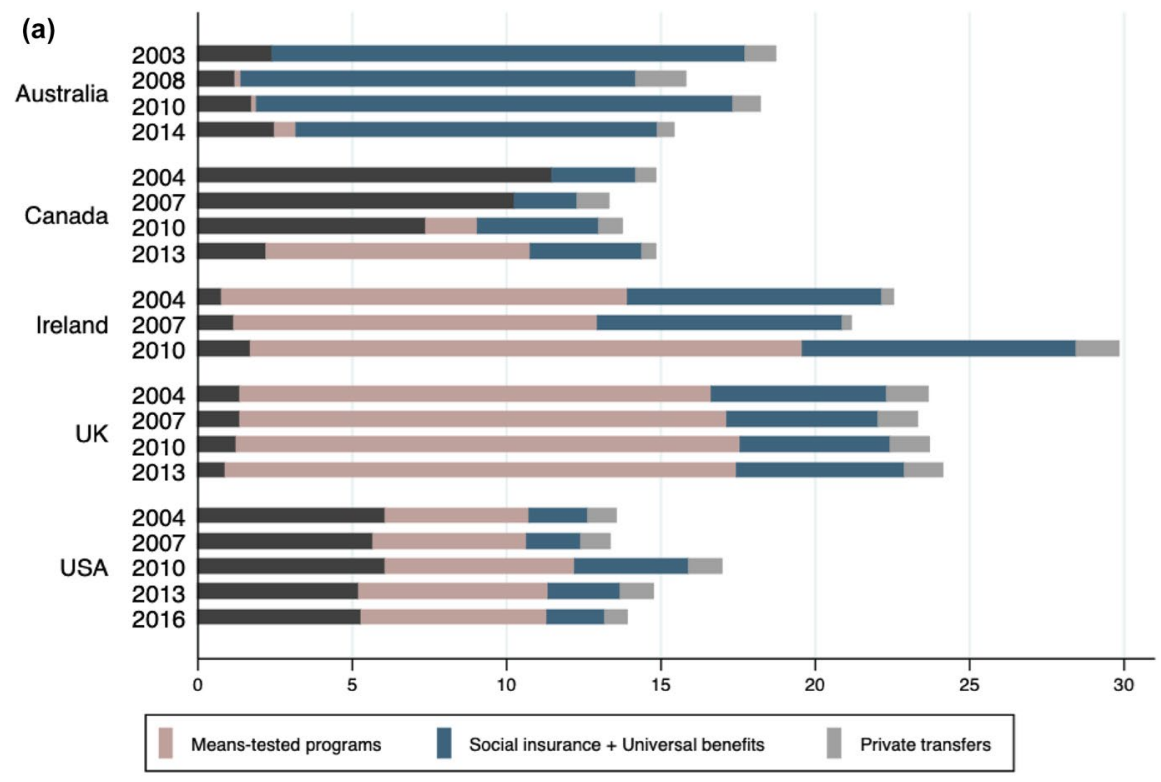

Note: The measure at the far right indicates the child poverty rate when a household only has access to market income. Source: Authors' calculation from LIS

(b)

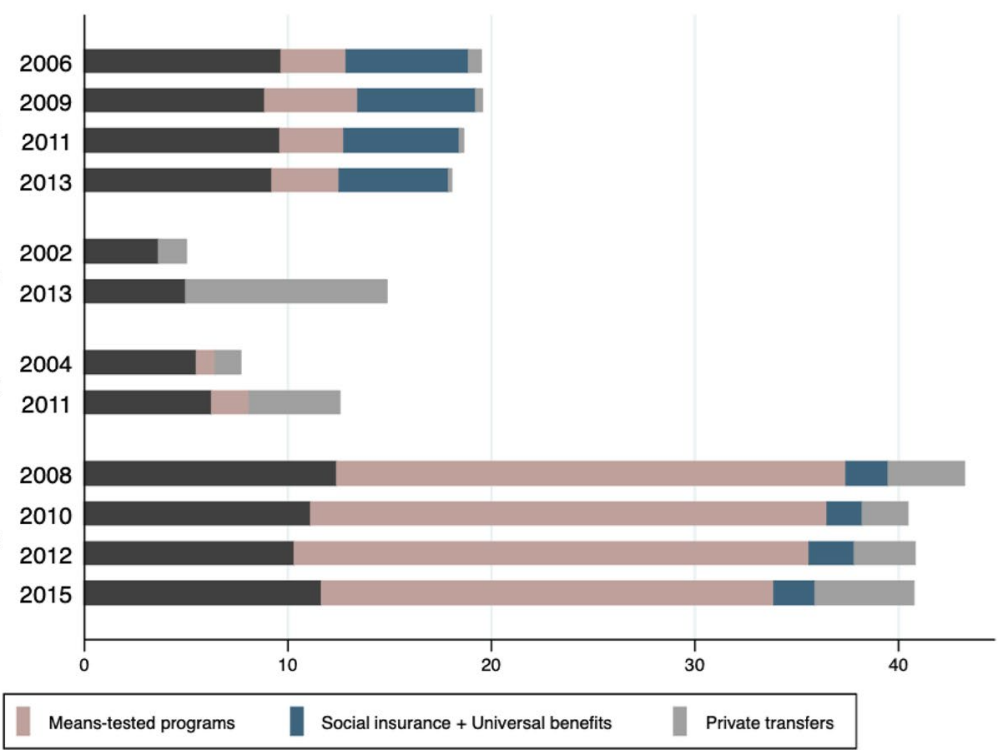

Note: The measure at the far right indicates the child poverty rate when a household only has access to market income Source: Authors' calculation from LIS

Fig. 3 a Reduction in deep child poverty across Anglo-Saxon high-income countries. b Reduction in deep child poverty across upper middle-income countries 
median equivalised disposable income, to examine the marginal effects of each component of a given household's economic resources, incrementally and cumulatively, on changes in child poverty. We begin by estimating the market-income poverty rates, and then integrating private transfers into household income packages. We report two further sets of deep poverty rates based on (1) additional consideration of social insurance and universal programs as sources of income, and (2) the combination of means-tested benefits with net of tax and social security contributions.

In Fig. 3a, results suggest that among Australian children living in households that survive on only market income plus occupational pensions, around $15.4 \%$ could be regarded as existing in conditions of deep poverty. Supplementing market income with private transfers, such as child support and other inter-household transfers, can yield only a slight reduction in the deep child poverty, lowering it to $14.9 \%$. Similarly, it is possible to observe the very limited role that private transfers play in reducing deep child in four other Anglophone nations. When social insurance and universal programs, however, supplement the addition of private transfers, this combination can serve as a promising mode of reducing deep child poverty: by about $12 \%$ points in Australia, 9\% points in Ireland, 5\% points in the UK, 4\% points in Canada and only $2 \%$ points within the US. Yet, Canadian estimates for poverty reduction will soon be doubled as their new and generous child allowance benefit comes online in the 2016 LIS data (Corak 2017). It is worth noting that meanstested transfers, along with net tax pay-outs (e.g. in work benefits from the tax system), further reduce the deep poverty rate among children to less than $1 \%$ in the UK, to about $1.7 \%$ in Ireland, to $2.5 \%$ in Australia, and to $2.2 \%$ in Canada, while leaving slightly higher rates of $5.3 \%$ in the US.

When we turn to four $\mathrm{MICs}^{7}$ in Fig. 3b, it is possible to observe a different account of poverty reduction story than the one we see in Anglophone nations. In South Africa, an overwhelming proportion (41\%) of children would live in deep poverty if only market income were available. When households possess both market income and private transfers, the deep child poverty rate is reduced to $36 \%$, which suggests that private transfers play a significant role in redeeming children from circumstances of deep poverty. Similarly, taking private transfers into account reduces deep child poverty rates in India by $4.5 \%$ points. In Brazil and South Africa, the deep child poverty rates are reduced by another $2-6 \%$ points when social insurance and universal benefits are added to a household income that was originally limited to market income and private transfers. More importantly, taking means-tested programs and tax payments into account yields a reduction of another $22 \%$ points from the deep child poverty rate in South Africa, while analogous programs in Brazil and India would reduce deep poverty rates by another $2-3 \%$ points.

We take a further step, to illustrate how the weights of different income components account for the total reduction in deep child poverty rates for each nation and shed light on which interventions may merit further attention. In Fig. 4, we calculate the extent to which private transfers, social insurance, universal benefits, and net means-tested transfers contribute to the overall reduction in deep child poverty rates

\footnotetext{
${ }^{7}$ Data from China regarding distinction of universal benefits, assistance benefits and private transfers is unavailable.
} 


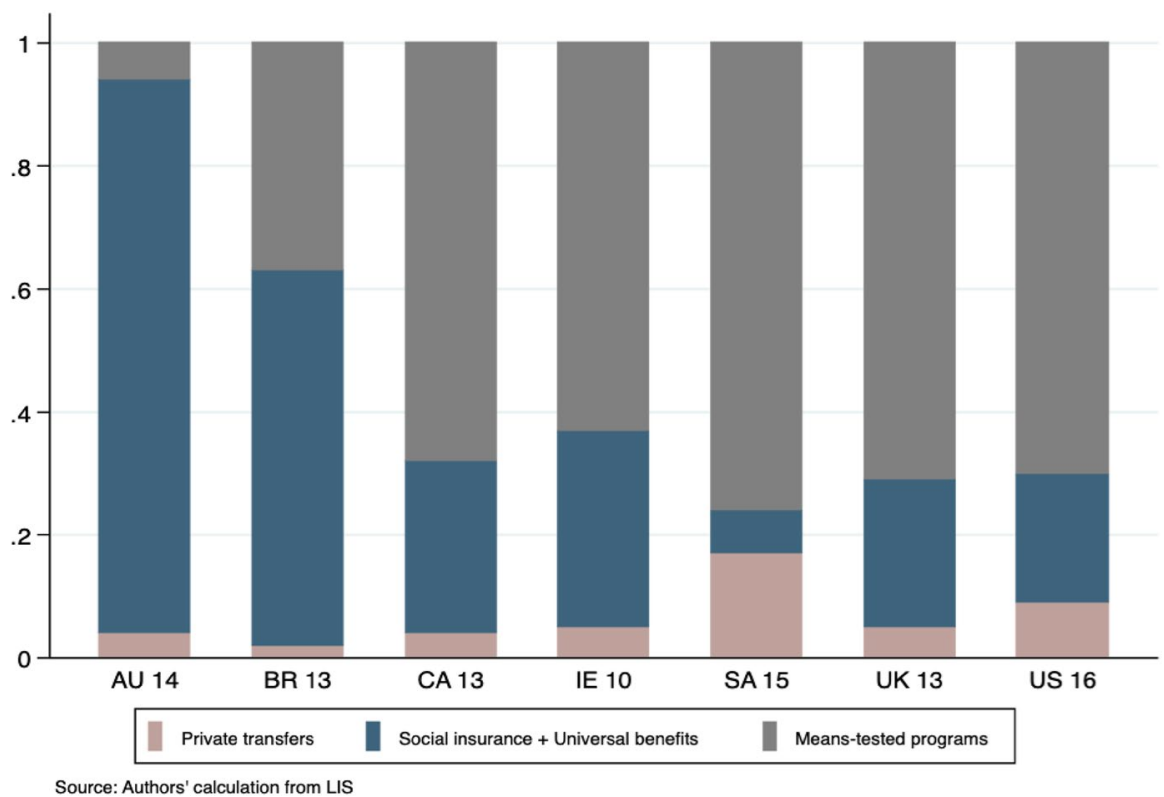

Fig. 4 Percentage of deep child poverty reduction that each income component accounts

within each respective country. With the exception of Australia, where the reduction of deep child poverty is disproportionally due to social insurance and universal programs, across all of the other countries we have examined, net means-tested benefits play a substantial role in reducing deep child poverty; the most significant illustration of this (76\%) can be observed in South Africa, but reduction rates range from 71 to $29 \%$ in the other nations. In addition, social insurance and universal programs contribute disproportionally to the reduction of Brazil's deep child poverty rate, relative to the contributions of such programs in the four Anglophone nations, Australia excepted.

\section{Discussion and Conclusion}

In recent years, many have questioned better ways to consistently measure child poverty across countries, especially among traditionally high-income nations and emerging upper-middle-income countries. As several larger economies have been reclassified as upper-middle-income nations, poverty reduction has become a main goal, which has led to a strong need to revisit issues regarding comparability in measurements of child poverty in countries with large differences in terms of their living standards and welfare regimes.

This paper contributes to the existing literature on poverty studies in two ways. First, instead of choosing one time point of a country for comparison, we estimated the trends of data of deep and extreme child poverty in two clusters of HICs and 
MICs to trace the poverty dynamics among this vulnerable population and to assess any progress that has been made over time under different social program provisions and welfare regimes. Second, we employ two equivalence scales to capture the absolute extreme poverty level and adjust the fixed poverty lines over time for inflation using the national CPI throughout the period examined to estimate the different level poverty rates across these countries, through which we aim to offer new insights into the efforts of poverty measures via a more consistent channel.

Understandably, income is underreported in all the surveys we consider. Some detailed studies on the underreporting of income were carried out in the US. Recent articles by Mittag (2019) and Meyer et al. (2019) discuss these adjustments. One method of adjustment for underreporting comes from the Urban Institute's TRIM3 model (Wheaton 2008), which adjusts for the underreporting of some kinds of benefits. A recent report by National Academies of Sciences, Engineering, and Medicine (2019) demonstrates that TRIM reduces baseline deep poverty (measured at half the SPM line) among children from 4.9 to $2.9 \%$. Mittag (2019) finds that TRIM overadjusts for underreporting, suggesting that factor alone should move the "correct" TRIM estimate above 3\%. Meyer et al. (2019) use administrative data to adjust for benefit underreporting and mainly discuss extreme poverty (at $\$ 2$ a day). They find that few persons live yearlong on incomes below $\$ 2$ a day after all adjustments are made, many of them based on dubious principles (e.g. removing households who are not asset-poor but not adjusting for debts, and so on). They also adjust for selfemployment, but we have already excluded the lowest-income self-employed people in our figures. These adjustments move many extremely poor people to the deeply poor category, and Meyer et al. (2019) find that those moved up by the receipt of inkind benefits appear to be among the most materially deprived Americans.

We concede that our US estimates most likely overstate the proportion of deep poverty among US children. Of course, we might find the same tendencies in other nations, but clearly the US estimate is still an outlier: approximately $5.3 \%$ are deeply poor in Fig. 1 (panel A), which might fall to 3\% after adjusting for benefit underreporting, compared to $2 \%$ or less for all other rich nations studied here for which no adjustments at all have been made. Moreover, as a complement to the traditional estimates from the World Bank on extreme poverty among whole population, our report on deep and extreme poverty among children still differs from the World Bank's in terms of the approach applied. With the assumption that economies of scale exist in household consumption and the concerns of self-employed households, our estimates might profile extreme poverty in developed nations more accurately. Similar to the patterns reported by Newhouse et al. (2017), we found that child poverty rates are higher than adult poverty ratios in all countries studied, regardless of which equivalence scale is used. That being said, it is demonstrated that 1 in 30 children in the US experiences homelessness every year (Bassuk et al. 2014). A nontrivial proportion of homeless children has long been excluded from most surveys due to high mobility, which ought to draw our attention.

Our aim is to foster a better understanding of what severe child deprivation problems look like in a global context and what could be done in terms of safety nets or poverty-oriented economic growth to lift the poorest children out of poverty. We also tried to explore what other factors may have key influences on deep child 
poverty rates. In addition to the trends of deep and extreme poverty for each nation, we estimated the market income poverty levels; addressed the comparative roles of private transfers, social insurance, and universal benefits; and targeted cash as well as near-cash transfers and taxes on deep poverty.

The prevalence of large-scale social programs in Brazil, South Africa, and India demonstrates a response by the Global South to material deprivation. We observed a substantial reduction in child poverty in all four MICs during the examined period, with India experiencing the most dramatic drop. These trends were driven both by overall economic growth, which reduces market income poverty, and by income supports that raise family incomes and add in investments in health and education to better prepare children and each nation for further growth. In the latest years examined, interventions in public benefit systems became more prevalent in the MICs relative to their previous periods, with substantial reductions that resulted from conditional cash transfer (CCT) programs occurring in Brazil and South Africa.

Although less-developed nations tend to lean more on private transfers as they have relatively fewer comprehensive social protection systems, Brazil appeared to have smaller proportions of inter-household transfer flows; instead, universal programs gradually became a vital means of reducing deep child poverty, along with the gradually stronger social assistance. ${ }^{8}$ India, however, stands out with its large inter-household transfer payments as its major means of helping to lift impoverished children out of poverty. In addition, South African social assistance ${ }^{9}$ appeared robust in terms of benefiting the deep poor.

The antipoverty effects of a household's income package in disadvantaged households with children varied across the nine countries of interest in terms of their levels of reliance on public transfers or private support in fighting against deep poverty. Compared to other high-income counterpart nations, the US constantly experienced higher child poverty rates, regardless of the relative or absolute terms. Social insurance and universal programs in the US tend to be meager compared to those in other high-income countries, and the overall portion that the US contributes to reducing its deep child poverty is far lower than the portion Brazil contributes. While the overall reduction of deep poverty in the US is mostly due to means-tested programs, private transfer flows are also non-ignorable. A recent proposal for an unconditional monthly child allowance in the United Sates would eliminate deep child poverty at a very reasonable cost, were it implemented (Shaefer et al. 2018). It is also worth noting that, in the most recent year, Canada and Ireland increased their spending on

\footnotetext{
${ }^{8}$ Brazil has a long history of implementing cash transfer programs and is the pioneering country in Latin America in using them as an instrument of social programs. In addition to its universal coverage of healthcare, the conditional cash transfer program-Bolsa Família, the largest CCT program in the world-acts as a vital means of social assistance for needy families with children to reduce short-term poverty and improve long-term human capital, as it requires beneficiaries to ensure that their children fulfill educational goals and health requirements.

9 Despite the inadequate results concerning its long-term impact and concerns about sustainable funding, as a means-tested program in South Africa, the Child Support Grant plays a significant role in assisting low-income families and their children. In terms of targeting, this largest flagship social-assistance program has also done a good job: It covered only $10 \%$ of poor children when it was introduced in 1998 , but it reached $85 \%$ in 2015 (11.7 million children; Oosthuizen 2007).
} 
social assistance programs, which substantially reduce deep or extreme poverty rates among children to tangibly lower levels, even when the effects are not yet shown. The primary results show that nations with universal benefits do better in lifting children out of deep or extreme poverty than those with targeted programs alone in rich nations (Brady and Burroway 2012). In contrast, private transfers and remittances from relatives abroad as well as conditional cash transfers benefit the poorest children in the middle-income countries. We conclude that some type of a universal child benefit—complementing basic public health care and education—is needed to eradicate long-term child poverty in all types of nations.

Open Access This article is distributed under the terms of the Creative Commons Attribution 4.0 International License (http://creativecommons.org/licenses/by/4.0/), which permits unrestricted use, distribution, and reproduction in any medium, provided you give appropriate credit to the original author(s) and the source, provide a link to the Creative Commons license, and indicate if changes were made.

\section{References}

Allen RC (2017) Absolute poverty: when necessity displaces desire. Am Econ Rev 107(12):3690-3721

Almond Douglas, Currie Janet, Duque Valentina (2018) Childhood circumstances and adult outcomes: act II. J Econ Lit 56(4):1360-1446

Alston P (2017) Statement on visit to the USA, United Nations Special Rapporteur on Extreme Poverty and Human Rights. http://www.ohchr.org/EN/NewsEvents/Pages/DisplayNews.aspx?NewsI $\mathrm{D}=22533 \&$ LangID=E. Accessed 5 Mar 2018

Alvaredo F, Chancel L, Piketty T, Saez E, Zucman G (2017) World inequality report 2018. The World Inequality Lab, Berkeley

Atkinson AB (2015) Inequality: what can be done?. Harvard University Press, Cambridge

Atkinson AB (2016) Monitoring global poverty: report of the commission on global poverty. The World Bank, Washington, DC

Bassuk EL, DeCandia CJ, Beach CA, Berman F (2014) America's youngest outcasts: a report card on child homelessness. The National Center on Family Homelessness, Newton

Brady D, Burroway R (2012) Targeting, universalism, and single-mother poverty: a multilevel analysis across 18 affluent democracies. Demography 49(2):719-746

Cai Y, Evans M (2018) Informal transfers in comparisons of income distributions: lessons from rich and middle-income countries. J Income Distrib 26(2):1-20

Corak M (2017) Innovation in cash benefits to families with children: the Canada child benefit. https ://milescorak.files.wordpress.com/2017/07/text-corak-national-academysciences-engineering-medic ine-child-poverty.pdf. Accessed 10 Apr 2018

Deaton A (2018) The US can no longer hide from its deep poverty problem. The New York Times. https ://www.nytimes.com/2018/01/24/opinion/poverty-united-states.html. Accessed 5 Mar 2018

Edin KJ, Shaefer HL (2015) \$2.00 a day: living on almost nothing in America. Houghton Mifflin Harcourt, Boston

Engle PL, Fernald LC, Alderman H, Behrman J, O'Gara C, Yousafzai A, Iltus S (2011) Strategies for reducing inequalities and improving developmental outcomes for young children in low-income and middle-income countries. Lancet 378(9799):1339-1353

Fernald LC, Gertler PJ, Neufeld LM (2008) Role of cash in conditional cash transfer programmes for child health, growth, and development: an analysis of Mexico's Oportunidades. Lancet 371(9615):828-837

Fernald LC, Gertler PJ, Neufeld LM (2009) 10-Year effect of Oportunidades, Mexico's conditional cash transfer programme, on child growth, cognition, language, and behaviour: a longitudinal follow-up study. Lancet 374(9706):1997-2005

Fox L (2017) The supplemental poverty measure: 2016. Current population reports, P60-261 (RV). US Census Bureau, Washington, DC 
Gao Q (2017) Welfare, work, and poverty: social assistance in China. Oxford University Press, Oxford

Gao Q (2018) China's fight against poverty: rallying all forces to eradicate poverty by 2020. In: Stepan M, Duckett J (eds) Serve the people: innovation and IT in China's social development agenda. Mercator Institute for China Studies (MERICS) Papers on China No. 6, Berlin

Gertz G, Kharas H (2018) The road to ending poverty runs through 31 severely off track countries. https ://www.brookings.edu/blog/futuredevelopment/2018/02/13/the-road-to-ending-poverty-runs-throu gh-31-severely-off-track-countries/. Accessed 10 Apr 2018

Gornick JC, Jäntti M (2012) Child poverty in high- and middle-income countries: selected findings from LIS (child poverty insights). UNICEF Policy and Strategy, New York

Gornick JC, Nell E (2017) Children, poverty, and public policy: a cross-national perspective (no. 701). LIS working paper series

Gornick JC, Smeeding TM (2018) Redistributional policy in rich countries: institutions and impacts in nonelderly households. Annu Rev Sociol 44:441-468

Heinrich CJ (2018) Presidential address:"a thousand petty fortresses": administrative burden in US immigration policies and its consequences. J Policy Anal Manag 37(2):211-239

Hickel K (2015) Could you live on $\$ 1.90$ a day? That's the international poverty line. https://www.thegu ardian.com/global-development-professionals-network/2015/nov/01/globalpoverty-is-worse-thanyou-think-could-you-live-on-190-a-day. Accessed 10 Apr 2018

Jencks C (2016) Why the very poor have become poorer. The New York Review of Books. http://www. nybooks.com/articles/2016/06/09/why-the-very-poor-have-become-poorer/. Accessed 5 Mar 2018

Kanbur R (2012) Aid to the poor in middle income countries and the future of the international development association. J Int Commer Econ Policy 3(02):1250008

Kanbur R, Sumner A (2012) Poor countries or poor people? Development assistance and the new geography of global poverty. J Int Dev 24(6):686-695

Luxembourg Income Study (LIS) Database (2019) Multiple countries. LIS, Luxembourg. http://www. lisdatacenter.org. Accessed September 2017 to April 2018

Magnuson KA, Votruba-Drzal E (2008) Enduring influences of childhood poverty. University of Wisconsin-Madison, Institute for Research on Poverty, Madison

Meyer BD, Wu D, Mooers VR, Medalia C (2019) The use and misuse of income data and extreme poverty in the United States (no. w25907). National Bureau of Economic Research, Washington, DC

Mittag N (2019) Correcting for misreporting of government benefits. Am Econ J Econ Policy 11(2):142-164

Moffitt R, Pauley G (2018) Trends in the distribution of social safety net support after the Great Recession. Stanford Center on Poverty and Inequality. http://www.econ2.jhu.edu/people/Moffitt/safet y_net_distribution_trends.pdf. Accessed 10 June 2018

National Academies of Sciences, Engineering, and Medicine (2019) A roadmap to reducing child poverty. The National Academies Press, Washington, DC. https://doi.org/10.17226/25246

Newhouse D, Becerra PS, Evans M (2017) New global estimates of child poverty and their sensitivity to alternative equivalence scales. Econ Lett 157:125-128

Oosthuizen M (2007) Consumer price inflation across the income distribution in South Africa. http:// www.dpru.uct.ac.za/sites/default/files/image_tool/images/36/DPRU\%20WP07-129.pdf. Accessed 5 Aug 2018

Pinkovskiy M, Sala-i-Martin X (2018) Shining a light on purchasing power parities (no. w24419). National Bureau of Economic Research, Washington, DC

Rainwater L, Smeeding TM (2003) Poor kids in a rich country: America's children in comparative perspective. Russell Sage Foundation, New York

Ravallion M, Chen S (2013) A proposal for truly global poverty measures. Glob Policy 4(3):258-265

SAHRC and UNICEF (2016) Global goals for every child: progress and disparities among children in South Africa. UNICEF South Africa, Pretoria

Shaefer HL, Collyer S, Duncan G, Edin K, Garfinkel I, Harris D, Yoshikawa H (2018) A universal child allowance: a plan to reduce poverty and income instability among children in the United States. RSF Russell Sage Found J Soc Sci 4(2):22-42

Shei A, Costa F, Reis MG, Ko AI (2014) The impact of Brazil's Bolsa Família conditional cash transfer program on children's health care utilization and health outcomes. BMC Int Health Hum Rights 14(1):10

Short K (2013) The research supplemental poverty measure: 2012. Current Population Reports. US Census Bureau, Washington, DC 
Smeeding T (2016) Poverty measurement. The Oxford handbook of the social science of poverty. Oxford University Press, $\mathrm{p} 21$

Smeeding T, Thévenot C (2016) Addressing child poverty: how does the United States compare with other nations? Acad Pediatr 16(3):S67-S75

Stevens A (2019) Safety net enables faster, more permanent exit from deep poverty. Center For Poverty Research, UC Davis. https://poverty.ucdavis.edu/sites/main/files/file-attachments/stevens_deep_ poverty_brief.pdf. Accessed 25 July 2019

Sulia V, Zikhali P (2018) Overcoming poverty and inequality in South Africa: an assessment of drivers, constraints and opportunities (English). World Bank Group, Washington, DC

Trump D (2018) Executive order reducing poverty in America by promoting opportunity and economic mobility. The White House, Washington, DC. https://www.whitehouse.gov/presidential-actions/ executive-order-reducing-poverty-america-promoting-opportunity-economic-mobility/. Accessed 25 Apr 2018

UNICEF and World Bank Group (2016) Ending extreme poverty: a focus on children. https://www.unice f.org/publications/files/Ending_Extreme_Poverty_A_Focus_on_Children_Oct_2016.pdf. Accessed 5 Mar 2018

Waldfogel J (2010) Britain's war on poverty. Russell Sage Foundation, New York

Wheaton L (2008) Underreporting of means-tested transfer programs in the CPS and SIPP. Urban Institute, Washington, DC

Wimer C, Smeeding TM (2017) USA child poverty: the impact of the Great Recession. Children of austerity: impact of the Great Recession on child poverty in rich countries. The United Nations Children's Fund and Oxford University Press, p 297

World Bank (2018a) Historical classification by income. https://datahelpdesk.worldbank.org/knowledgeb ase/articles/906519-world-bank-country-andlending-groups. Accessed 10 Apr 2018

World Bank (2018b) Poverty and shared prosperity 2018: piecing together the poverty puzzle. World Bank, Washington, DC

Publisher's Note Springer Nature remains neutral with regard to jurisdictional claims in published maps and institutional affiliations. 